\author{
Izabela SKRZYPCZAK ${ }^{1}$ \\ Lidia BUDA-OŻóG ${ }^{2}$ \\ Marta SŁOWIK ${ }^{3}$
}

\title{
TRWAŁOŚĆ JAKO POSTULAT ROZWOJU ZRÓWNOWAŻONEGO
}

\begin{abstract}
Niekontrolowana degradacja obiektów i związane z nią rosnace koszty na remonty i renowacje oraz przedwczesne rozbiórki to nie tylko problem techniczny, ale i ekonomiczny. Znaczna część problemów trwałości konstrukcji wynika z różnic w prowadzeniu budowy i produkcji beton. Na trwałość wpływają warunków dojrzewania oraz jakości wykonania. W związku z tym, bardzo ważne jest opracowanie ulepszonej podstawy oceny trwałości konstrukcji z betonu, a więc szacowania trwałości kontrolowanej. Trwała konstrukcja powinna przez cały projektowy okres użytkowania spełniać wymagania ze względu na stany graniczne nośności oraz stany graniczne użytkowalności bez istotnego obniżenia przydatności lub nadmiernych, nieprzewidzianych kosztów utrzymania. Wymaganą ochronę konstrukcji należy ustalać, biorąc pod uwagę planowane zastosowanie, projektowy okres użytkowania, program utrzymania oraz oddziaływania. W niniejszym artykule, omówiono aktualne zalecenia dotyczące oceny trwałości konstrukcji z betonu. Porównano zalecenia zaproponowane w PN-EN-1992, PN-EN-1990, PN-EN 206-1 oraz MC 2010. Zaproponowano formułę do oceny trwałości poszczególnych elementów konstrukcyjnych oraz całej konstrukcji w odniesieniu do oddziaływania środowiska. Konstrukcja z betonu może być uznana za wystarczająco trwałą, jeżeli poszczególne części poddawane badaniu wykazują wyższe wartości współczynników trwałości od współczynników środowiska. Ocena trwałości może być przeprowadzona w dwóch etapach. Pierwszy etap może zostać przeprowadzony, kiedy konstrukcja jest wykonywana. Drugi etap kiedy wykonanie rzeczywistej konstrukcji nie jest zgodne z planem budowy. Analizując trwałości materiałów zwrócono uwagę na trzy aspekty: trwałość kontrolowaną, przebadaną i projektowaną.
\end{abstract}

Słowa kluczowe: konstrukcje betonowe, trwałość, oddziaływanie środowiska

\footnotetext{
1 Autor do korespondencji: Izabela Skrzypczak, Politechnika Rzeszowska, ul Poznańska 2, izas@prz.edu.pl

${ }^{2}$ Lidia Buda-Ożóg, Politechnika Rzeszowska, ul Poznańska 2, lida@prz.edu.pl

${ }^{3}$ Marta Słowik, Politechnika Lubelska, ul Nadbystrzycka 40, m.slowi@pollub.pl
} 


\section{Wprowadzenie}

Przez wiele lat trwałość konstrukcji betonowych i żelbetowych była traktowana marginalnie, a niekontrolowana degradacja obiektów i związane z nią rosnące koszty na remonty i renowacje oraz przedwczesne rozbiórki to nie tylko problem techniczny, ale i ekonomiczny. Zaistniała sytuacja to również nieracjonalne wykorzystanie zasobów naturalnych, a tym samym problem środowiskowy. W celu zmniejszenia skutków omawianego zjawiska, wiele prac badawczych na temat trwałości konstrukcji zostało przeprowadzonych w ostatnich latach, a rezultaty włączone do aktualnych zaleceń normowych.

Znaczna część problemów trwałości konstrukcji wynika z różnic w prowadzeniu budowy i produkcji betonu, uzależniona jest od warunków dojrzewania oraz jakości wykonania. Czynniki te mogą zanegować wszystkie potencjalne korzyści płynące z lepszych specyfikacji materiałowych i dobrego projektu.

W związku z tym, bardzo ważne jest opracowanie ulepszonej podstawy oceny trwałości konstrukcji z betonu, a więc szacowania trwałości kontrolowanej. W niniejszym artykule, omówiono aktualne zalecenia w ocenie trwałości konstrukcji z betonu, jak również zaproponowano formułę oceny trwałości konstrukcji i materiałów budowlanych w odniesieniu do oddziaływania środowiska.

\section{Trwałość a zalecenia normowe}

Obiekty inżynierskie należy zaprojektować i wykonać tak, aby w przyjętym okresie użytkowania i poziomie utrzymania była zapewniona ich trwałość, rozumiana jako zdolność użytkowania obiektu przy zachowaniu cech wytrzymałościowych i eksploatacyjnych, których miernikiem są stany graniczne nośności oraz stany graniczne użytkowalności. Przyjęty okres użytkowania, odnoszący się do trwałości obiektów inżynierskich, może dotyczyć:

- całego obiektu - jako średnia trwałość podstawowych elementów, które nie podlegających okresowej wymianie,

- podstawowych elementów obiektu, tj. podpór, dźwigarów i pomostu,

- elementów podlegających okresowej wymianie.

Projektowanie na trwałość to spełnienie wymagań podstawowych i użytkowych. Konstrukcje należy w taki sposób projektować, aby zmiany następujące $\mathrm{w}$ projektowym okresie użytkowania, $\mathrm{z}$ uwzględnieniem oddziaływań środowiska i przewidywanego poziomu utrzymania, nie obniżały właściwości użytkowych konstrukcji poniżej zamierzonego poziomu (Rys. 1).

W celu zapewnienia odpowiedniej trwałości konstrukcji zaleca się uwzględniać: zamierzone lub przewidywane użytkowanie konstrukcji, wymagane kryteria projektowe, oczekiwane warunki środowiskowe, skład, właściwości i zachowanie się materiałów i wyrobów, właściwości gruntu, rodzaj ustroju konstrukcyjnego, kształt elementów i szczegóły konstrukcyjne, jakość wykonania i poziom kontroli, szczególne środki zabezpieczające, zamierzone utrzyma- 


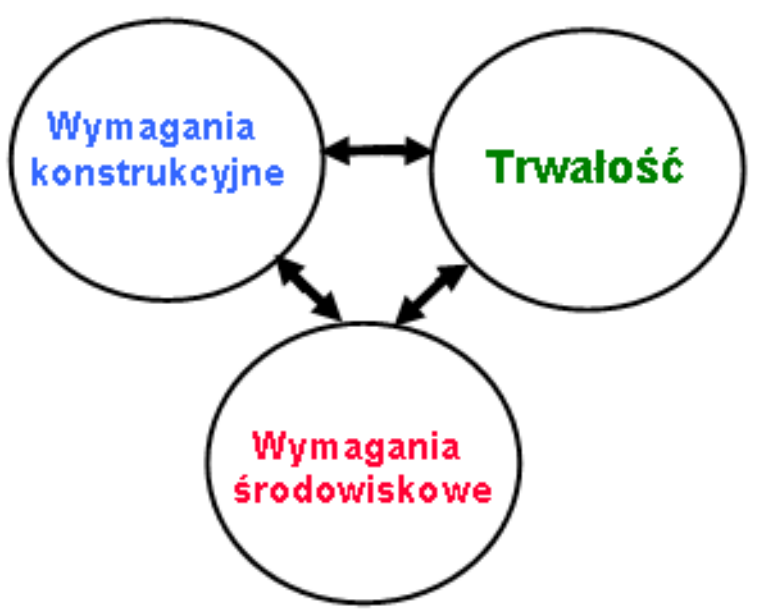

Rys.1. Schemat projektowania zintegrowanego

Fig.1. Scheme of integrated design

nie w projektowym okresie użytkowania. Zalecenia te stanowią jedynie podstawę do wstępnych uzgodnień projektanta $\mathrm{z}$ inwestorem. Nie stanowią one konkretnych wskazówek ilościowych, ani jakościowych do założeń projektowych. Na etapie projektowania należy określić warunki środowiskowe, tak aby można było ocenić ich znaczenie $\mathrm{z}$ uwagi na trwałość i podjąć odpowiednie środki w celu ochrony materiałów stosowanych w konstrukcji. Na podstawie obliczeń, badań doświadczalnych oraz doświadczenia zebranego z wcześniejszych realizacji można określić przewidywany stopień deterioracji całej konstrukcji oraz jej elementów.

Podstawowe zalecenia dotyczące projektowania ze względu trwałość można znaleźć w rozdział 4 Eurokodu 2[1], Eurokodu 0 [2] i normy PN-EN 206-1 [3]. Trwała konstrukcja powinna przez cały projektowy okres użytkowania spełniać wymagania ze względu na użytkowalność, nośność i stateczność, bez istotnego obniżenia przydatności lub nadmiernych, nieprzewidzianych kosztów utrzymania. Wymaganą ochronę konstrukcji należy ustalać, biorąc pod uwagę planowane zastosowanie, projektowy okres użytkowania, program utrzymania oraz oddziaływania. Należy rozpatrzyć potencjalną rolę oddziaływań bezpośrednich i pośrednich warunków środowiska. Należy uwzględnić ochronę stali przed korozją poprzez odpowiedni stopień zagęszczenia zbrojenia, jakość i grubość otuliny betonowej czy kontrolowane zarysowanie. Zagęszczenie i jakość otulenia osiąga się, kontrolując maksymalny współczynnik wodno-cementowy i minimalną zawartość cementu [3], które mogą być związane z minimalną klasą betonu. Wystawione na działanie środowiska elementy metalowe, które mogą podlegać przeglądom i wymianie, można zabezpieczać powłokami ochronnymi. W innych przypadkach należy je wykonywać $\mathrm{z}$ materiału odpornego na korozję. W szczególnych przypadkach, należy wziąć pod uwagę wymagania dodatkowe (dla kon- 
strukcji o charakterze tymczasowym lub monumentalnym, konstrukcji poddanych oddziaływaniom wyjątkowym itd.) $[5,7]$.

W Eurokodzie 2 cz. 1-1 [1] wskazano szczegółowe zalecenia związane $\mathrm{z}$ uwzględnieniem trwałości $\mathrm{w}$ projektowaniu. W Załączniku E podano minimalne klasy wytrzymałości betonu ze względu na trwałość, odniesione do klas ekspozycji, podano minimalne otulenie wymagane ze względu na trwałość $\mathrm{c}_{\text {min- }}$ dur, odpowiednio dla stali zbrojeniowej i dla stali sprężającej, podano wymagane dodatki otuliny oraz możliwe redukcje otuliny związane $\mathrm{z}$ klasą konstrukcji oraz ewentualnym stosowaniem dodatkowych zabezpieczeń (np. powlekanie betonu, stal nierdzewna) [1,7].

Przy projektowaniu można odnieść się również do pomocniczej tablicy Zalecane wartości graniczne dla sktadu i właściwości betonu w normie PN-EN 206-1 [3] , w której zawarto zalecenia w odniesieniu do minimalnej klasy wytrzymałości, maksymalnego stosunku w/c, minimalnej zawartości cementu $\mathrm{w}$ mieszance dla poszczególnych klas ekspozycji (w tym klas XF dotyczących zamrażania/odmrażania) oraz minimalnej zawartości powietrza $\mathrm{w}$ przypadku klas ekspozycji XF.

Problematyka trwałości w normie Model Code 2010 [4] odniesiona jest do: projektowanego okresu użytkowania w przypadku projektowania nowych konstrukcji, pozostałego okresu użytkowania w przypadku konstrukcji istniejących, wzmacnianych, remontowanych lub modernizowanych. Problematykę trwałości w MC 2010 [4] ograniczono do podejścia uznanego za wystarczające oraz unikania zniszczenia. Wymagania szczegółowe do projektowania, doboru materiałów i wykonawstwa powinny być określone jednym z dwóch sposobów: na podstawie statystycznej oceny wyników eksperymentalnych i obserwacji polowych, na podstawie kalibracji danych z wieloletniego doświadczenia.

Podejście oparte na „unikaniu zagrożenia” w zakresie projektowania na trwałość wymaga wykazania, że proces zniszczenia nie zajdzie w wyniku takich zabiegów jak: odizolowanie konstrukcji od oddziaływań środowiska, stosowanie niereaktywnych, oddzielenie od czynników reaktywnych, np. utrzymanie stopnia zawilgocenia poniżej poziomu krytycznego, przeciwdziałanie szkodliwym reakcjom, np. za pomocą metod elektrochemicznych.

W celu weryfikacji trwałości w MC 2010 [4] zaproponowano cztery metody: pełne podejście probabilistyczne, podejście półprobabilistyczne - częściowe współczynniki, podejście „uznane za wystarczające”, podejście „unikanie zniszczenia". Zagadnienie doboru otuliny zbrojenia w MC2010 [4] ujęto podobnie jak w Eurokodzie 2 [1], czyli wartości minimalne zależą od: wymagań technologicznych, przyczepności i zakotwienia, wymagań przeciwpożarowych, wymagań trwałości. W zakresie trwałości, minimalna otulina zależy od odporności betonu na wpływ substancji chemicznych w kombinacji z agresywnością środowiska oraz od projektowego okresu użytkowania konstrukcji. Wskazania szczegółowe w odniesieniu do otuliny ograniczono do przykładowej tablicy dla betonów klasy co najmniej C20/25 i okresu użytkowania 50 lat. Zalecono ogól- 
nie, aby dla okresu użytkowania 100 lat powiększyć otulinę odpowiednio o 30\%. Zalecenia zawarte w [4] są znacznie mniej precyzyjne niż te zawarte w Eurokodzie 2 [1] oraz w komentarzach np. [6].

Podejście „unikanie zniszczenia" jest spełnione, gdy stan depasywacji nie może wystąpić w wyniku trwałej odporności na karbonatyzację, albo gdy oddziaływanie środowiska jest wyeliminowane, albo ma miejsce trwała odporność zbrojenia na korozję [7]. W MC2010 [4] wprowadzono problematykę ,zarządzania cyklem istnienia konstrukcji" (Life Cycle Management) za pomocą dwóch dokumentów dla konstrukcji. Pierwszy z nich to dokumentacja okresu powstania obiektu (,As-Built Documentation”), zakończona „,ertyfikatem narodzin" (Birth Certificate Document - $B C D$ ), zawierającym wyniki wstępnego przeglądu nowej konstrukcji. Drugi dokument to dokumentacja okresu użytkowania (Service-Life File), zawierająca rejestrację wszystkich działań podejmowanych w okresie użytkowania oraz warunków użytkowania, a w przypadku wykonania poważniejszych prac remontowych uzupełniona "certyfikatem ponownych narodzin" (Re-Birth Certificate Document - RCD).

\section{Trwałość}

W celu określenia trwałości kontrolowanej zaproponowano formułę do oceny trwałości konstrukcji i materiałów budowlanych w odniesieniu do oddziaływania środowiska. Trwałość poszczególnych elementów konstrukcji betonowych można sprawdzić, zgodnie z poniższą nierównością, w której współczynnik trwałości $\left(\mathrm{W}_{\mathrm{T}}\right)$, powinien być nie mniejszy niż współczynnik środowiska $\left(\mathrm{W}_{\dot{\mathrm{S}}}\right)$.

$$
\mathrm{W}_{\mathrm{T}}>\mathrm{W}_{\dot{\mathrm{S}}}
$$

Zaproponowane równanie (1) zastosować można do oceny trwałości poszczególnych elementów konstrukcyjnych, jak i całej konstrukcji. Konstrukcja $\mathrm{z}$ betonu może być uznana za wystarczająco trwałą, jeżeli poszczególne części poddawane badaniu wykazują wyższe wartości współczynników trwałości od współczynników środowiska. Ocena trwałości może być przeprowadzona w dwóch etapach. Pierwszy etap może zostać przeprowadzony, kiedy konstrukcja jest wykonywana. Na tym etapie czynniki w odniesieniu do materiałów i prac budowlanych można przyjmować do weryfikacji założeń i obliczeń projektowych. Drugi etap, równanie nie jest spełnione w pierwszym etapie, wykonanie rzeczywistej konstrukcji nie jest zgodne z planem budowy. Na tym etapie, dane dotyczące szczegółów konstrukcyjnych, jakości materiałów i warunków prac budowlanych są niezbędne do poprawy ich trwałości.

Trwałość obiektu budowlanego składającego się z szeregu pojedynczych elementów konstrukcyjnych, w którym zniszczenie jednego elementu powoduje awarię całej konstrukcji można wyznaczyć z zależności: 


$$
\mathrm{W}_{\mathrm{T}}=\mathrm{U}_{\mathrm{i}=1}^{\mathrm{n}}\left(\mathrm{W}_{\mathrm{i}}\right)
$$

Jeżeli elementy w modelu (konstrukcji) są w pełni skorelowane to prawdopodobieństwo zniszczenia na n- elementów jest równe prawdopodobieństwu zniszczenia najbardziej narażonego na oddziaływanie środowiska elementu:

$$
\mathrm{W}_{\mathrm{T}}=\max _{\mathrm{i}}\left[\mathrm{W}_{\mathrm{i}}\right]
$$

Natomiast dla elementów, które nie są w pełni skorelowane i nie są rozłączne to prawdopodobieństwo awarii można tylko oszacować. Cornell [8] dla systemów szeregowych proponuje następujące oszacowanie prawdopodobieństwa awarii:

$\max _{\mathrm{i}}\left[\mathrm{W}_{\mathrm{i}}\right] \leq \mathrm{W}_{\mathrm{T}} \leq \sum_{\mathrm{i}}\left[\mathrm{W}_{\mathrm{i}}\right]$

Poszczególne wskaźniki trwałości i środowiska można obliczyć korzystając z poniższej formuły (5):

$$
\begin{aligned}
& \mathrm{W}_{\mathrm{i}}=\frac{1}{\mathrm{n}} \mathrm{W}_{1} \mathrm{~W}_{2} \mathrm{~W}_{3} \ldots \mathrm{W}_{\mathrm{n}}\left(\mathrm{w}_{1}+\mathrm{w}_{2}+\mathrm{w}_{3}+\ldots+\mathrm{w}_{\mathrm{n}}\right) \\
& 0 \leq \mathrm{W}_{\mathrm{i}} \leq 1 ; \quad \mathrm{W}_{\mathrm{j}}=1 \quad \text { lub } 0 ; \quad 0 \leq \mathrm{w}_{\mathrm{i}} \leq 1
\end{aligned}
$$

gdzie: $\mathrm{W}_{\mathrm{i}^{-}}$wskaźnik trwałości lub środowiska obliczony jako liczba z przedziału $[0,1]$

$\mathrm{W}_{1}, \mathrm{~W}_{2}, \mathrm{~W}_{3}, \ldots \mathrm{W}_{\mathrm{n}}$ - zdeterminowane wartości krytycznych parametrów analizowanego wskaźnika,

$\mathrm{w}_{1}, \mathrm{w}_{2}, \mathrm{w}_{3}, \mathrm{w}_{\mathrm{n}}-$ wartości parametrów sterowalnych (kontrolowanych).

Wzór (5) składa się z członu multiplikatywnego i addytywnego. Każdy z nich pełni odmienną funkcję.

Rolą członu multiplikatywnego jest umożliwienie rozróżnienia trwałości poszczególnych elementów konstrukcyjnych:

- elementu dobrego, którego stopień trwałości będzie określony na dalszym etapie oceny,

- elementu wadliwego, w stosunku, do którego nie przeprowadza się dalszej oceny.

Wartości $\mathrm{W}_{\mathrm{j}}$ wchodzące $\mathrm{w}$ skład pierwszego członu odnoszą się do parametrów krytycznych. Parametry krytyczne to te, których zakres zmienności jest ściśle ograniczony. Mogą to być ograniczenia od dołu, od góry lub dwustronne. Charakterystyczną cechą wyróżników $\mathrm{W}_{\mathrm{j}}$ jest to, że mogą przyjmować tylko dwie wartości 1 lub 0. Jeśli wartość parametru, którego dotyczy, mieści się w zakresie 
zmienności dopuszczalnym przez odpowiednie przepisy, to $\mathrm{W}_{\mathrm{j}}=1$. Jeżeli parametr nie mieści się $\mathrm{w}$ dopuszczalnym przedziale zmienności, $\mathrm{W}_{\mathrm{j}}$ przyjmuje wartość 0 . Iloczynowa forma członu wzoru (5) sprawia, że wystarczy, aby jeden z parametrów krytycznych $\mathrm{W}_{\mathrm{j}}$ równy był zero, a wówczas niezależnie od wartości pozostałych, wskaźnik trwałości $\mathrm{W}_{\mathrm{T}}$ będzie równy zero. $\mathrm{W}$ takiej sytuacji konstrukcja będzie uznana za nie spełniająca wymagań w odniesieniu do trwałości bez potrzeby badania wartości pozostałych parametrów. Zadaniem członu addytywnego jest umożliwienie dalszego zróżnicowania trwałości. Konstrukcja wzoru i zastosowanie $\mathrm{w}$ drugim członie wzoru wielkości z przedziału $[0,1] \mathrm{w}_{\mathrm{i}}$ umożliwia uwzględnienie ważności oraz specyfiki wpływu zmiany poszczególnych parametrów na ocenę trwałości.

Wyróżnienie parametrów krytycznych spośród ogółu parametrów oceny trwałości i wpływu środowiska jest umowne. Ma ono na celu wyodrębnienie parametrów szczególnie ważnych, o stosunkowo niewielkim przedziale zmienności i wyraźnie określonych granicach, które w żadnym wypadku nie mogą być przekroczone. Przekroczenie granic tolerancji przez parametr krytyczny nie może być kompensowane nawet najbardziej korzystnymi wartościami pozostałych parametrów oceny. Konstrukcja, której to dotyczy musi być uznana za nie spełniającą wymagań trwałości. Na przykład jeżeli nie spełnione są wymagania dotyczące rodzaju składników betonu lub otulenia zbrojenia. Parametr krytyczny dostarcza informacji o trwałości konstrukcji Parametr posiada dwa wyróżniki $\mathrm{W}_{\mathrm{j}}$ oraz $\mathrm{W}_{\mathrm{i}}$. Mogą więc wystąpić trzy sytuacje kiedy:

- parametr ma tylko jeden wyróżnik $\mathrm{W}_{\mathrm{j}}$,

- parametr ma dwa wyróżniki $\mathrm{W}_{\mathrm{j}}$ oraz $\mathrm{w}_{\mathrm{i}}$,

- parametr ma tylko wyróżnik $\mathrm{w}_{\mathrm{i}}$.

Przypadek pierwszy dotyczy parametrów, których dopuszczalny przedział zmienności musi mieścić się w określonych granicach, przy czym dla oceny trwałości nie ma znaczenia w którym punkcie przedziału tolerancji znajdować się będą konkretne wartości tych parametrów.

Przypadek drugi dotyczy parametrów, których dopuszczalny przedział zmienności jest ściśle określony i nie jest obojętne, w którym punkcie dopuszczalnego przedziału zmienności znajdować się będą konkretne wartości parametrów w przedziale zmienności istnieje ognisko.

Przypadek trzeci dotyczy parametrów, które mają stosunkowo duże dopuszczalne przedziały tolerancji, o niezbyt wyraźnie określonych granicach i nie mogą być podstawą dyskwalifikacji ocenianej konstrukcji w odniesieniu do trwałości. Mają one swoje ognisko i wartości tych parametrów stanowią informację uzupełniającą dla określenia trwałości.

Przypadek pierwszy dotyczy sytuacji, kiedy przyrost wartości parametru w obrębie przedziału tolerancji zawsze wprowadza korzystną zmianę w poziomie trwałości. Wartość takiego parametru można opisać trójkątną liczbą rozmytą. 
Przypadek 1

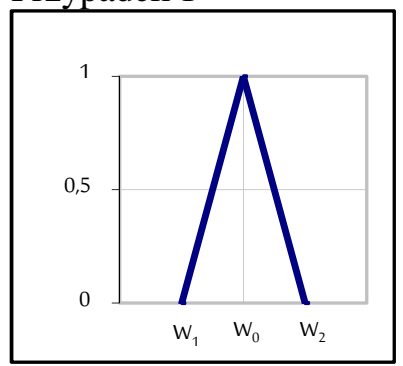

Przypadek 2

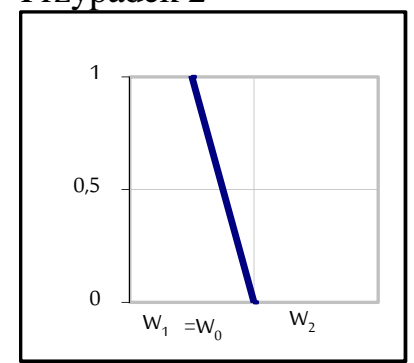

\section{Przypadek 3}

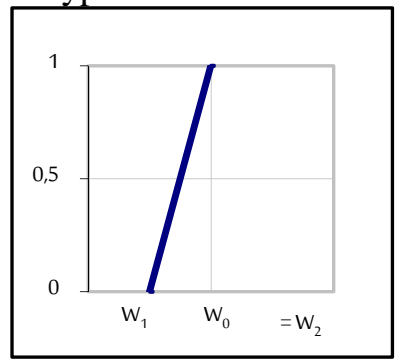

Rys. 2. Parametry jakości opisane liczbą rozmytą $\mathrm{w}=\left(\mathrm{W}_{0}, \mathrm{~W}_{1}, \mathrm{~W}_{2}\right)$

Fig. 2. Quality parameters described by diffuse number $w=\left(W_{0}, W_{1}, W_{2}\right)$

Punkt $\mathrm{W}_{1}$ jest dolną granicą przedziału tolerancji. Punkt $\mathrm{W}_{0}$ oznacza taką wartość parametru $\mathrm{W}_{0}$, która $\mathrm{w}$ pełni spełnia wymagania stawiane parametrowi. Wartości większe od $\mathrm{W}_{0}$ nie zmieniają już stanu trwałości konstrukcji. Przypadek drugi dotyczy sytuacji, kiedy przesunięcie w lewo lub w prawo od wartości optymalnej oznaczają zawsze niekorzystne zmiany poziomu trwałości. Przypadek trzeci dotyczy sytuacji, kiedy przyrostowi wartości parametru w całym przedziale tolerancji odpowiada obniżenie poziomu trwałości konstrukcji. Na osi poziomej punkt $\mathrm{W}_{2}$ oznacza górną granicę tolerancji, punkt $\mathrm{W}_{1}$ oznacza wartość parametru, od którego przyrostowi wartości $\mathrm{W}$ towarzyszyć będą korzystne zmiany poziomu trwałości konstrukcji. Liczba wyróżników $\mathrm{W}_{\mathrm{j}} \mathrm{i} \mathrm{w}_{\mathrm{i}}$ zależy od zakresu i dokładności przeprowadzanej oceny ( im więcej parametrów tym bardziej kompleksowa ocena trwałości konstrukcji). Przedstawiony model stanowi jedynie koncepcję oceny poziomu trwałości konstrukcji. Jej celem jest umożliwienie oceny trwałości konstrukcji z zachowaniem jak największego stopnia obiektywności.

\section{Wnioski}

Projektowanie konstrukcji budowlanych obejmuje minimalizację wpływu środowiska na konstrukcję w całym okresie użytkowania, przy spełnieniu wymagań projektowania konstrukcyjnego i projektowania na trwałość. Projektowanie na trwałość to uwzględnienie przede wszystkim odporności konstrukcji na wpływy środowiskowe przekazywane na konstrukcję. W artykule zaproponowano formułę oceny trwałości konstrukcji i materiałów budowlanych w odniesieniu do oddziaływania środowiska. Analizując trwałość materiałów należy zwrócić uwagę na trzy aspekty: trwałość kontrolowaną, przebadana i projektowana. Projektując konstrukcje odnosimy się do projektowanego okresu użytkowania nie uwzględniając ryzyka ponoszenia dodatkowych kosztów na ewentualne nieprzewidziane remonty. Dlatego bardzo ważna jest kompleksowa analiza wpływu środowiska na trwałości poszczególnych elementów i całego obiektu budowlanego. 


\section{Literatura}

[1] PN-EN 1992-1-1 Eurokod 2: Projektowanie konstrukcji z betonu. Część 1-1: Reguły ogólne i reguły dla budynków. PKN.

[2] PN-EN 1990 Eurokod 0: Projektowanie konstrukcji. PKN.

[3] PN-EN 206-1: 2003 Beton. Część 1: Wymagania, właściwości, produkcja i zgodność, PKN.

[4] Model Code 2010, First complete draft, fib Bulletin 56, Volume 1, March 2010.

[5] Ajdukiewicz A., Aspekty trwałości i wpływu na środowisko w projektowaniu konstrukcji betonowych, Przegląd Budowlany, 2/2011, s. 20-29.

[6] Czarnecki L.: Beton według normy PN-EN 206-1- komentarz- Praca zbiorowa, Polski Cement i PKN, Kraków, 2004.

[7] Kuliński M., http://warunkibudowlane.pl/?s=modulos\&v=capitulo\&c=15410.

[8] Nowak A.S, Collins K.R: Reliability of Structures. McGraw-Hill Higher Education, 2000.

\section{DURABILITY AS A POSTULATE OF SUSTAINABLE DEVELOPMENT}

\section{S u m m a r y}

An uncontrolled degradation of structures and costs of repairs and renovations as well as a premature demolition connected with this degradation, is not only a technical but also an economical issue. A large part of the durability problem is due to differences between concrete construction and production. The durability of concrete structures depends on quality of conformance and maturation conditions. So it is very important to develop the improved base for estimation concrete structure durability, and thus to estimate the controlled durability. Durable structures should meet the requirements due to ultimate and serviceability limit states without a significant reduction of reusability or excessive, unforeseen costs of conservation. The required design protection should be determined taking into account the intended use, the useful life of the design, maintenance and impacts. In the paper, the current recommendations for the evaluation of concrete structures durability are discussed. The recommendations proposed in the PN-EN-1992, PN-EN-1990, PN-EN 206-1 and MC 2010 have been than compared. The formula for estimating the whole structure durability and durability of building materials has been proposed according to the influence of environment. Concrete structure can be considered as sufficiently stable when every tested part shows higher values of durability compared to environmental values. Durability assessment can be carried out in two stages. The first stage can be carry out, when the structure is under construction and the second stage when the execution of the real structure disagrees with the construction plan. When analising the materials durability, the authors have paid the attention on three aspects: controlled, tested and designed durability.

Keywords: concrete structures, influence of environment, durability

Przestano do redakcji: 10.12 .2014 r.

Przyjęto do druku: 22.06.2015 r.

DOI:10.7862/rb.2015.68 
